\title{
The Dynamics of Open, Peer-to-Peer Learning: What Factors Influence Participation in the P2P University?
}

\author{
June Ahn, Cindy Weng, Brian S. Butler \\ University of Maryland College Park \\ juneahn@umd.edu,weng.cindy@gmail.com, bsbutler@umd.edu
}

\begin{abstract}
Online learning has matured as a mechanism that can change how we deliver education. Open education resources are proliferating, and institutions are creating massive open online courses (MOOCs). In addition, efforts are underway to develop platforms that allow individuals to create, lead, and participate in their own courses. This bottom-up, peer-to-peer model of education illuminates new dilemmas. For example, open learning environments are heavily dependent on voluntary individual participation, but such participation is difficult to foster. In this paper, we use log data from the Peer 2 Peer University $(P 2 P U)$ to explore factors related to active participation in a series of teacher, professional development courses (the P2PU School of Education). We employ learning analytics to identify how features such as course page design and course organizer activity interact with new and returning participants to foster increased participation in open learning groups.
\end{abstract}

\section{Introduction}

Researchers and pundits have long suggested that online learning will transform education delivery [6]. With increased access to computing and the Internet, and a growing number of freely available educational resources and platforms, these predictions are gradually coming about. As Brown and Adler [3] note, the widespread availability of the Internet, education resources, and social media creates a perfect storm of opportunity for new models of education delivery.

Many strategies populate the ecosystem of online learning. Open education resources (OER) are increasing. Venues such as MIT's Open CourseWare Initiative share class syllabi. Video lectures are freely available on platforms such as the highly publicized Khan Academy. Higher education institutions are creating massively open online courses (MOOCs) in partnership with Coursera, Udacity, and EdX. These MOOCs have attracted participation from hundreds of thousands of learners. Finally, use of social media encourages individuals to mobilize, collaborate, and create their own peer-to-peer education opportunities.

In this study, we examine such a learning platform, the Peer 2 Peer University (P2PU). P2PU allows individuals to create and lead their own open courses. We begin by describing how P2PU differs from other online learning environments such as MOOCs and learning management systems (LMSs) used in traditional college courses. We highlight the importance of participation in collective learning environments. We then draw from the broader research literature on online communities and e-learning to hypothesize factors that may influence levels of active participation in a peer-to-peer learning platform.

Using longitudinal fixed-effects models, we empirically examine two interrelated aspects of active participation in P2PU courses: the number of participants who contribute each week and the average level of comment contribution (i.e. average comments per participant). Weekly data from a set of P2PU courses is used to test hypotheses about the impact of course organizer activity, course webpage design, and participant status on the level of active participation.

The reported findings and overall approach inform design recommendations for fostering participation. Our study illustrates how log data can be used to measure and model factors affecting participation and other aspects of peer-led open courses. We demonstrate how learning analytics of data culled from P2PU contributes theoretical and design insights about collective learning dynamics in open environments.

\section{Related Work}

\subsection{The P2P University and the Challenge of Driving Participatory Learning}

The Peer 2 Peer University (http://p2pu.org) is a grassroots open education project founded in 2010. The P2PU platform is designed to promote community learning through free, peer-led courses. Any registered member of P2PU can develop and lead a course that other members can then join and participate in. A 
course organizer designs course pages outlining weekly topics, links to educational content, and activities for learners. Course organizers might create pages with links to articles or prompts that ask participants to discuss particular topics in a given week. All courses are developed by P2PU members and they run effectively because of the participation of other peers in the platform.

Although all P2PU courses are free and voluntary, members joining a course select a designation that indicates their commitment to the learning group. Joining as a participant, signals a deeper commitment to contribute to a course. Members can also join as followers, which signals an interest in the course but makes lesser commitment to contribute.

In addition to supporting open creation of courses, P2PU partners with various organizations to create clusters of courses that follow a theme. For example, in this study, we obtained log data from the initial implementation of the P2PU School of Education (SOE). The SOE is a cluster of teacher professional development courses, developed by educators for other educators. Our data includes courses that ran from August-November 2011. After consultation with directors from P2PU and a review of relevant research, we chose to use this data to explore a fundamental issue that was salient in the implementation of SOE and other P2PU courses - the challenge of fostering active participation.

To understand the importance of participation in an environment such as P2PU, it is helpful to examine how this form of online learning differs from other common examples. One can view P2PU as a form of collective learning where large groups of individuals aggregate their participation to develop learning communities [15]. A collective environment differs from other commonly studied collaborative learning environments along dimensions such as group size, leadership, division of labor, and level of compulsory participation (see Table 1).

In P2PU, members can join any course that is offered on the platform, thus the potential group size can scale out to the collective. Leadership in P2PU courses is distributed. Organizers structure courses, but they are not instructors in the traditional sense. Leadership of the learning activities is distributed across members who join the course and voluntarily choose to participate. The division of labor is more distributed in a peer-to-peer model. In a collective context such as P2PU, each participant can influence the learning process via multiple pathways such as their comments, suggestions to change the course structure, or engagement in peer-assessment.

Finally, perhaps the most salient difference

Table 1. Features of P2PU as a Collective Learning Environment.

\begin{tabular}{|c|c|}
\hline Feature & Formal Face-to-Face or Blended Course vs. P2PU Course \\
\hline Group Size & $\begin{array}{l}\text { In formal course settings (e.g. college) group sizes are bounded by course enrollment. } \\
\text { Activities such as discussion often occur in small groups (e.g. } 4-5 \text { students). } \\
\text { In P2PU, any of the thousands of members can join a course. Courses involve larger } \\
\text { groups of like-minded, interested learners, and can scale out to the collective. }\end{array}$ \\
\hline Leadership & $\begin{array}{l}\text { In formal course settings, an instructor is the clear leader of the course. } \\
\text { In P2PU, course organizers structure and take ownership for leading a course. However, } \\
\text { they are not the instructor in the traditional sense, but rather a guide who facilitates the } \\
\text { peer-to-peer interaction and learning. Each learner is expected to contribute and lead the } \\
\text { learning process of the group. }\end{array}$ \\
\hline Division of Labor & $\begin{array}{l}\text { In formal course settings, the instructor handles particular responsibilities such as } \\
\text { lecturing and grading. Students take on particular roles, such as completing instructor- } \\
\text { defined assignments. Participants must contribute significantly for group success, and } \\
\text { lack of active participation is clearly visible. } \\
\text { In P2PU, the organizer creates the initial course structure. However, the activities and } \\
\text { learning process evolve as peer members contribute to the course, make suggestions, and } \\
\text { contribute new ideas for the course. The division of labor to run the course is distributed } \\
\text { across participants. Members can join as core participants, or as peripheral followers and } \\
\text { an individual's lack of contribution is not salient to others. }\end{array}$ \\
\hline $\begin{array}{l}\text { Compulsory } \\
\text { Participation }\end{array}$ & $\begin{array}{l}\text { In formal course settings, participation such as discussion can be made compulsory (e.g. } \\
\text { as part of a student's grade or an official assignment of the syllabus). } \\
\text { In P2PU, all participation is entirely voluntary, which brings increased challenges to } \\
\text { fostering and encouraging sustained participation in courses. }\end{array}$ \\
\hline
\end{tabular}


between formal course settings and P2PU are mechanisms for compulsory participation. In formal courses, instructors can design compulsory participation such as making online posting a part of a student's grade or designating online activities as required assignments. In open, informal platforms such as P2PU, participation is entirely voluntary and based on the interests and motivations of each member. Because of the dependence on peer contribution for discussion and content development, questions about how to foster active participation, create active learning groups, and design for collective learning interactions are particularly critical. Without ways of addressing these challenges, the potential of collective learning environments will not be realized.

Open online learning initiatives often take a topdown approach to promoting widespread participation. High profile MOOCs such as Coursera, Udacity, and EdX deliver courses in partnership with highly prestigious institutions such as Stanford, Harvard, and MIT. In contrast, P2PU follows a model espoused by original definitions of MOOCs, which is fundamentally about bottom-up, peer-to-peer learning where individuals connect to resources and other learners via online platforms [20]. Members organize and collaboratively lead each other through courses. Courses are by one or more organizers, but are not formally taught by them in a traditional sense. The collective group drives the learning process. Course content is generated by the contributions of members. Learners in P2PU join courses based on personal interest and a desire to participate in a community of like-minded learners. Questions remain about how open, peer-to-peer educational environments can best be designed to encourage sufficient active participation from learners.

In the next section, we draw from the broader literature in online communities and e-learning to highlight several factors that are both present in the P2PU environment and likely to affect the level of active participation in open online courses.

\subsection{Factors in Online Communities Related to Member Participation}

In P2PU a primary method of participation is through comments on course pages. Thus, this analysis focuses on the volume of comments contributed to P2PU courses and the level of contribution by individual learners. At the outset, we recognize two caveats. First, prior research in online communities and learning has noted that participation comes in many forms. Comments may be the 'unit' of contribution to an online community, but their function can vary. They may differ with respect to the level of interactivity they promote [25], how they foster social bonds and community among members [12,17], or the kinds of knowledge building that occurs [11]. We recognize that participation comes in rich forms and examining the volume of comments necessarily obscures this richness [13]. The data available for this study allows for consideration of levels of comment contribution, but not analysis of the nature of these comments.

Second, the relationship between participation and learning also requires careful explication. Prior studies suggest that there is a positive correlation between online participation (e.g. contributing to course forum discussion) and learning outcomes such as student grades [8,9]. Conversely, social learning and literacy perspectives suggest that learning is defined by participation and the two concepts cannot be disentangled $[13,14]$. Both perspectives recognize that participation in online communities represents an important step in learning, either as a precursor to learning or as a reflection of the learning process itself.

One way to examine the vibrancy of an online learning group is to consider the overall activity, or total number of comments contributed. Theories of elearning posit that features such as course design or instructor activity influence activity within a learning group [10]. However, examination of ways of attracting more comments should not taken as advocating technological determinism or neglecting the cultivation of the human actors that do the contributing. Rather, we suggest that fostering sufficient activity within an online learning group is a necessary precondition that is largely dependent on the ability to attract participants and motivate them to actively contribute.

Online communities have long struggled with the challenge of attracting participants and motivating contribution [18]. Large scale studies of e-mail list based groups, open source projects, and discussion forums have found that many online communities are subject to problems of under contribution, insufficient activity, and lack of critical mass [7]. For this reason, questions of attracting and motivating active participants have received significant amount of attention in both scholarly and practitioner literature $[16,24]$. The need to motivate active members in an online community informs the first general hypothesis in P2PU:

H1: Attracting a higher number of active participants (people who contribute comments) and encouraging them to engage more deeply in a course (more comments per commenter) will be positively correlated with higher levels of activity in a course (total number of comments contributed to course discussions). 
We also posit that particular features of the P2PU platform such as course design and course leader roles do not directly impact a group's activity level, but rather are mediated by the ability to attract members who engage more deeply.

Defining different types of participants is also highly salient. Prior research in online communities has found that in many contexts, the majority of individuals are "lurkers" who visit sites, read content, but never become active contributors [21]. However, while it may be tempting to characterize lurkers as free-riders, they are actually a critical element of successful online communities. Individuals who passively participate are important as because they are potential active participants. While it is possible for someone to enter an online social space and immediately become an active contributor, it is common for individuals to passively observe or read content prior to taking on the role of an active participant [24].

Just as individuals in online communities might develop from lurkers to active participants, members of online learning communities also develop over time. Factors such as a sense of community, shared commitment, and trust in learning groups take time to develop and require sustained interaction between members [9,11,17]. Participants of learning communities based in formal settings are typically already present (e.g. they are part of the class or cohort). In open learning communities, the presence of passive participants is a natural precursor to active participants. In the context of P2PU this suggests that:

H2: The number of participants who visit a P2PU site as passive participants will be positively correlated with the number of active participants.

This conceptualization of passive participants also implies that there will be differences between new arrivals and returning participants. Empirical studies of online communities have found that new arrivals respond differently to interface features and group discussion activity [1]. Practitioner recommendations and social theories of group engagement also argue that new participants differ from returning participants in terms of their relationship with the community [5]. In e-learning groups, members may be more apt to participate as they've created relationships with others, become accustomed to the norms of the course, and developed social bonds and trust [12,17]. New participants may require more time and experience to convert into active participants. This suggests that, in P2PU courses:

H3a: The positive relationship between the number of returning participants visiting the course and the number of active commenters will be stronger than relationship between the number of new joiners and the number of active commenters.

Prior studies also suggest that returning participants will be more likely than new participants to engage deeply in a course (contributing more comments):

H3b: The positive relationship between the number of returning participants visiting the course and the average volume of comments per commenter will be stronger than the relationship between new joiners and average volume of comments per commenter.

In online communities there are individuals who take on the role of facilitating discussion and interaction [4]. Message contributions from these individuals, whether they are formally recognized or not, significantly affect the level of activity from others [23]. Prior studies of e-learning contexts also find that instructor behaviors greatly influence the types of interactions, collaboration, and learning activities students will enact in a course [2,10,11]. While P2PU course organizers may not be identified as formal discussion leaders, they are able to participate. Hence, organizers' contributions in discussions are expected to positively affect courses by encouraging more contributors and more activity from each active participant.

H4: The number of organizer comments will be positively associated with (a) the number of active participants and (b) their average level of comment contribution.

Another aspect of online community that has parallels in P2PU courses is content and materials. In a P2PU course the most prominent materials are the course pages for each week. In qualitative observation of the P2PU SOE courses, we found that some course pages explicitly prompted members to actively submit comments. In other weeks, such prompts were not present. In online communities, content such as introductory messages, FAQ, and Q\&A summaries have been found to significantly affect participation behavior and discussion dynamics [1]. Hence it is expected that:

H5: The number of explicit discussion prompts in course materials will be positively related to (a) the number of active participants and (b) the extent of their average level of contribution.

Lastly, as noted above, it has been shown that different aspects of a community can have different impacts on new and returning participants [5]. This raises the possibility that organizer comments and discussion prompts may differentially affect new and 
returning individuals' participation behaviors. To explore these possibilities our analysis will consider the interactions between the number of new and returning participants and the volume of organizer comments and explicit discussion prompts.

\section{Methodology}

\subsection{Study Sample and Initial Dataset}

To test the hypotheses about active participation, this study uses data from the first offering of the P2PU School of Education (SOE), which occurred in late 2011. The SOE was a cluster of seven teacher professional development courses. P2PU provided log data for these classes that described user activity during a three-month (13-week) period from the end of August 2011 to the end of November 2011.

This study represents an initial partnership with $\mathrm{P} 2 \mathrm{PU}$ and is part of a larger research initiative to consider how to create publicly sharable datasets and conduct analyses of this widely used open education platform. All resources and interactions recorded in the P2PU platform are available under an open Creative Commons license. However, this dataset and future datasets from the larger project undergo a process of anonymization so that user identities are protected to the maximum extent possible. Identifying information and private messages between members are not included in the dataset, and only log data of site actions are available for analysis. The raw dataset contained both user and page data.

User Data. The raw dataset provided information about each member of each course including: (a) how they identified themselves within the course (organizer, participant, follower, or non-identified visitor), (b) the number of comments they made each day, (c) the time they spent on the course pages each day, and (d) rough measures of whether they visited only one page or viewed multiple pages in P2PU during a site visit.

Page Data. Log data was also provided for each course page. Page-specific data included (a) total time each user spent on the page, (b) whether page views were isolated or part of a series of page views on the site, and (c) total comments per page. Daily page data was also delineated by user.

Descriptive analysis of $\log$ data and direct examination of the $\mathrm{p} 2 \mathrm{pu}$.org pages were used to create descriptions of each course:

Group 1, Multimedia and Graphics to Facilitate Deeper Learning encouraged participant collaboration and knowledge sharing. It had 2 organizers, 16 participants, 38 followers, 564 visitors, and 16 pages.

Group 2: OER in the K-12 Classroom asked users to work in teams and assigned tasks every week. It had
2 organizers, 22 participants, 28 followers, 593 visitors, and 14 pages.

Group 3: Student Engagement was task-focused and only specified individual work. Discussion was encouraged and a long-term project was assigned. It had 2 organizers, 27 participants, 26 followers, 556 visitors, and 29 pages.

Group 4: Teaching in Online and Blended Classrooms assigned tasks every week that contributed to an overall project. The course could be completed individually or as a group. It had: 2 organizers, 23 participants, 36 followers, 661 visitors, and 26 pages.

Group 5: Using Web 2.0 and Social Media to Encourage Deeper Learning combined four types of weekly tasks (social, reflective, practical and project) with a course-long project. It had 3 organizers, 26 participants, 40 followers, 840 visitors, 37 pages.

Group 6: Writing \& Common Core: Deeper Learning for All focused on writing assignments and a course project. Participants were also asked to write on an outside blog or wiki. Weekly topics were introduced for discussion on the P2PU site. It had 2 organizers, 31 participants, 38 followers, 1157 visitors, and 20 pages.

Group 7: Differentiating Instruction used weekly tasks and a course project. However, participants were asked to use a Google group for discussion instead of the P2PU's pages. It had 3 organizers, 25 participants, 25 followers, 478 visitors, and 12 pages.

Overall P2PU SOE courses typically had 2-3 organizers, 20-30 participants, 20-40 followers, and around 600-1000 unidentified visitors. Courses began 5-6 weeks after registration opened in August 2011.

\subsection{Measures}

Using the P2PU log data, we created a multivariate longitudinal, panel dataset of 7 courses $x$ 13 weeks $(n=91)$. Each record measured activity in a given course in a particular week (e.g. course 1 in week 3). Starting with August 31, 2011 (the first date showing activity in any course), the daily log data was separated into 7-day weeks. Weeks were labeled 1 to 13 with the last week ending November 29, 2011 (the last date of recorded activity in any course). For each week, the following analysis variables were created:

Dependent Variable: Total Comments measures the overall level of active learner participation in a course in terms of the total number of comments participants contributed to the course in a given week.

Mediating Variables: We posit that overall level of active participation on a collective learning platform can be broken down into two related, but distinct subcomponents: the number of active commenters and the average level of contribution among those commenters. The number of active commenters is the 
total number of participants who contributed at least one comment to a course in a given week. The level of contribution is captured by the average comments per commenter, which is calculated by dividing the number of comments per week by the number of commenters for that week.

Independent Variables: Organizer Comments is the total number of comments contributed each week by course organizers. New Joiners indicates how many self-designated participants visited the course site for the first time during each week. New joiners was calculated using time-stamped user data to count users whose first activity in the course (e.g. a page view) occurred during the specified week. Returning Participants are members who previously joined the course as a self-designated participant and visited the P2PU course site (but didn't necessarily contribute a comment) in both the focal week and a prior week. Weekly post prompts measures how many course pages in a particular week explicitly asked participants to post comments or discussion. To derive this measure, we examined and coded each course page. Each page was examined to determine if it included an explicit posting prompt (e.g. "Post a comment."). The number of pages containing posting prompts was tallied to create weekly measures of the level of explicit prompts in each course. Descriptive summaries of the measures are included in Table 2.

Table 2. Descriptive Statistics

\begin{tabular}{ll}
\hline & Mean (Std. Dev.) \\
\hline Total Comments Contributed & $7.32(12.29)$ \\
Organizer Comments & $6.97(11.22)$ \\
New Joiners & $1.69(2.39)$ \\
Returning Participants & $4.84(4.84)$ \\
Weekly Post Prompts & $0.67(1.28)$ \\
Active Commenters & $2.62(3.84)$ \\
Comments per Commenter & $1.19(1.47)$
\end{tabular}

All values are per Course per Week $(\mathrm{N}=91)$

\section{Analysis and Findings}

We begin with descriptive analysis of different patterns of contributed comments. Courses typically see an initial increase in user participation, with a gradual but consistent drop-off over time (Figure 1). Some courses have a secondary spike in participation. One outlier is course 7, which had almost no user comments. As noted earlier, examination of the course pages indicated that organizers moved much of the course activity to an external Google group. Removing course 7 from the analyses did not alter results substantially, so the course was kept in the analysis dataset. The other courses had a wide range of activity, from almost none in some weeks to a maximum of 5060 comments in others.

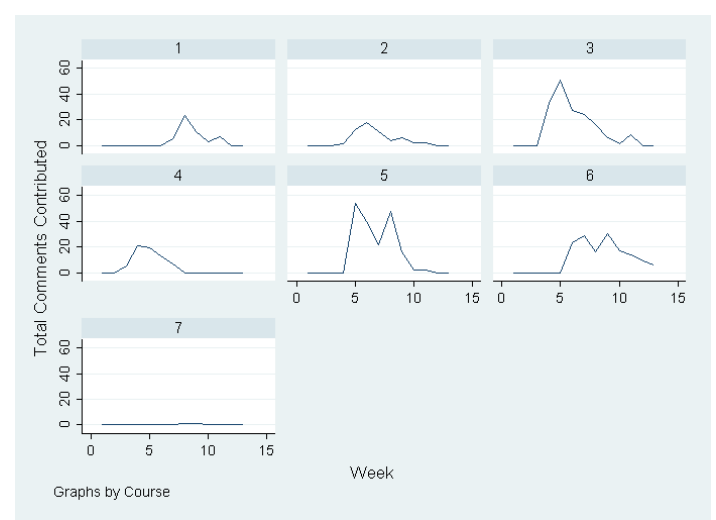

\section{Figure 1. Total Comments Contributed by Participants per week.}

\subsection{Model Analysis}

To test the proposed hypotheses we used Fixed Effects (FE) regression models. One advantage of the FE model is by controlling for each course as a fixed effect, researchers can control for unobserved variable bias for any factors or characteristics of courses that remain stable over time. We also note that this analysis considers activity in courses each week, which are not independent of one another. This non-independence poses a significant issue to the calculation of standard errors if there is large serial correlation between weeks. Post-hoc analysis found statistically non-significant serial correlation for 2 of the 3 models we present in this analysis. The model with Active Commenters as the dependent variable (Table 5) showed statistically significant correlation between weeks, although the size of the correlation was small. The ideal solution would be to account for clustered standard errors or use multilevel models. However, given the limitation of the log data in this instance (only 7 courses) we utilize the FE model with the caveat that there may be biases in the standard error calculations for the one model. The fixed effects model is expressed as:

$$
\mathrm{Y}_{\mathrm{it}}=\mathrm{B}_{1} \mathrm{X}_{\mathrm{it}}+\mathrm{B}_{2} \mathrm{X}_{\mathrm{it}}+\ldots+\mathrm{B}_{6} \mathrm{X}_{\mathrm{it}}+\alpha_{\mathrm{i}}+\mathrm{u}_{\mathrm{it}}
$$

$\mathrm{Y}_{\mathrm{it}}=$ Total Comments (contributed by participants) in course $\mathrm{i}$, and week $\mathrm{t}$

$\mathrm{B}_{1} \mathrm{X}_{\mathrm{it}} \ldots \mathrm{B}_{4} \mathrm{X}_{\mathrm{it}}=$ The independent variables (IVs) organizer comments, new joiners, returning participants, and weekly post prompts in course $\mathrm{i}$, and week $\mathrm{t}$

$\mathrm{B}_{5} \mathrm{X}_{\mathrm{it}} \ldots \mathrm{B}_{6} \mathrm{X}_{\mathrm{it}}=$ The hypothesized mediating variables (MVs) active commenters and avg. comments per commenter in course $\mathrm{i}$, and week $\mathrm{t}$ 
$\alpha_{\mathrm{I}}=$ An intercept for course $\mathrm{i}$

$\mathrm{u}_{\mathrm{it}}=$ the error term

We also included two control variables in the model: a binary variable indicating whether each course was officially running in a specific week (RunningYN), and time (week).

We ran three initial models (Table 3 ). The base model (Model 1) includes dummy variables for courses and the control variables. Model 2 includes the direct effects of the four main independent variables. Model 3 then adds the hypothesized mediating variables.

H1: Active Participants and Average Number of Comments per Participant are positively correlated to Total Course Activity. The fixed effects model results (Table 3) support the first hypothesis. In model 3, Active Commenters and Avg. Comments per Commenter were highly related to total course activity and statistically significant. The results confirm the basic expectation that encouraging participation in $\mathrm{P} 2 \mathrm{PU}$ courses involves mobilizing more members to be active and to contribute more deeply to the course.

Evidence for Mediation. We outline this finding, although it is expected and intuitive, to better clarify the relationship between factors such as organizer activity and overall levels of participation. The results indicate that factors such as organizer activity, weekly prompts, returning participants, and new joiners did not directly affect total comments (Model 3, Table 3). Rather, these factors influenced the presence of active commenters and avg. level of comments, which in turn affected the overall activity in a learning community.

In model 2 (Table 3), organizer comments, returning participants, and weekly prompts (to a lesser extent) are positively correlated with total comments. However, these positive relationships become insignificant when the presence of active commenters and average comment levels are included (Model 3). This suggests that factors such as organizer comments, weekly prompts, or returning participants are entirely mediated by active commenters and their average contributions. We conducted a multiple mediation analysis [22] to calculate the indirect effects of the IVs and test for significance (Table 4). The results show that organizer comments, returning participants, and weekly post prompts have significant indirect effects on fostering total comment contributions. These indirect effects are entirely mediated by the number of commenters and their level of participation.

H2: Number of participants that visit a P2PU course will be positively correlated to number of active commenters and avg. comments per commenter. We ran additional fixed effects regression analyses (with active commenters and avg. comments per commenter as the dependent variables)
Table 3. Fixed Effects Regression Results Predicting Total Comments (contributed by participants per Week)

\begin{tabular}{|c|c|c|c|}
\hline & $(1)^{\mathrm{a}}$ & (2) & (3) \\
\hline Active & & & $0.81 * *$ \\
\hline Commenters & & & \\
\hline $\begin{array}{l}\text { Avg. Comments } \\
\text { per Commenter }\end{array}$ & & & $0.37 * *$ \\
\hline Organizer & & $0.25 * *$ & -0.03 \\
\hline Comments & & & \\
\hline New Joiners & & 0.07 & -0.01 \\
\hline Returning & & $0.58 * *$ & -0.09 \\
\hline Participants & & & \\
\hline Weekly Post & & $0.15 *$ & 0.01 \\
\hline Prompts & & & \\
\hline $\mathrm{N}$ & 91 & 91 & 91 \\
\hline Adj. $R^{2}$ & 0.28 & 0.75 & 0.90 \\
\hline
\end{tabular}

Table 4. Multiple Mediation, Indirect Effects of IVs and Significance

\begin{tabular}{|c|c|c|}
\hline & $\begin{array}{c}\text { Total Indirect } \\
\text { Effect } \\
\text { (Through Active } \\
\text { Commenters and } \\
\text { Ave. Comments } \\
\text { per Commenter) }\end{array}$ & $\begin{array}{l}\text { Proportion } \\
\text { of Total } \\
\text { Effect that } \\
\text { is Mediated }\end{array}$ \\
\hline Organizer & $0.31 * *$ & \multirow[t]{2}{*}{1.13} \\
\hline Comments & $(0.07)$ & \\
\hline New Joiners & $\begin{array}{l}0.38 \\
(0.36)\end{array}$ & -- \\
\hline Returning & $1.78 * *$ & \multirow[t]{2}{*}{1.16} \\
\hline Participants & $(0.22)$ & \\
\hline $\begin{array}{l}\text { Weekly Post } \\
\text { Prompts }\end{array}$ & $\begin{array}{l}1.30 * * \\
(0.53)\end{array}$ & 0.93 \\
\hline $\begin{array}{l}\text { Standard errors in } \\
\text { Unstandardized c }\end{array}$ & $\begin{array}{l}\text { arentheses. }(* * \mathrm{p}<\text {. } \\
\text { efficients used to calc }\end{array}$ & ects \\
\hline
\end{tabular}

to test more specific hypotheses about how these factors might affect participation (Table 5).

The results provide partial support for $\mathrm{H} 2$, in that having more participants return and visit a P2PU course is positively correlated with more active commenters. Returning members are also positively correlated with more average contributions per commenter. These results suggest that encouraging learners to return and visit a course (even passively) is an important step in facilitating active contribution.

H3a: The relationship between the number of returning participants and number of active 
Table 5. Predictors Influencing Active Commenters and Avg. Number of Comments per Commenter

\begin{tabular}{|c|c|c|}
\hline & $\begin{array}{c}\text { Active } \\
\text { Commenters }\end{array}$ & $\begin{array}{l}\text { Avg. Comments } \\
\text { per Commenter }\end{array}$ \\
\hline $\begin{array}{l}\text { Organizer } \\
\text { Comments }\end{array}$ & -0.03 & $0.47 * *$ \\
\hline New Joiners & 0.00 & 0.02 \\
\hline $\begin{array}{l}\text { Returning } \\
\text { Participants }\end{array}$ & $0.59 * *$ & $0.56 * *$ \\
\hline $\begin{array}{l}\text { Weekly Post } \\
\text { Prompts }\end{array}$ & $0.24 *$ & $0.58 * *$ \\
\hline $\begin{array}{l}\text { Returning } \\
\text { Participants X } \\
\text { Post Prompts }\end{array}$ & $-0.25 *$ & $-0.46^{*}$ \\
\hline $\begin{array}{l}\text { New Joiners X } \\
\text { Post Prompts }\end{array}$ & $0.15^{*}$ & 0.05 \\
\hline $\begin{array}{l}\text { Returning } \\
\text { Participants X } \\
\text { Organizer } \\
\text { Comments }\end{array}$ & $0.36 * *$ & -0.13 \\
\hline $\begin{array}{l}\text { New Joiners X } \\
\text { Organizer } \\
\text { Comments }\end{array}$ & 0.01 & -0.21 \\
\hline $\mathrm{N}$ & 91 & 91 \\
\hline Adj. $R^{2}$ & 0.88 & 0.72 \\
\hline
\end{tabular}

commenters will be stronger than the relationship between new joiners and active commenters. Hypothesis $3 \mathrm{a}$ was supported. While the number of returning participants was positively correlated with active commenters, there was not a significant relationship between new joiners and active commenters. Thus, it appears that a key strategy is to focus on converting new joiners to return participants.

H3b: The relationship between the number of returning participants and the avg. comments per commenter will be stronger than the relationship between new joiners and avg. comments per commenter. Hypothesis $3 b$ was also supported. While having more returning participants was positively associated with more contributions per active commenter, the relationship with new joiners was not significant.

H4: Number of organizer comments will be positively correlated to (a) number of active commenters and (b) avg. comments per commenter. The results provided partial support for this hypothesis.
Organizer comments were not correlated to the presence of more active commenters (H4a). However, organizer comments were positively related to more average contributions per commenter (H4b).

H5: The number of explicit discussion prompts in course materials will be positively related to (a) the number of active commenters and (b) average comments per commenter. Hypothesis 5 was supported. The results show that the presence of more weekly post prompts in course pages was positively correlated with both more active commenters and more contributions per commenter.

Interaction Effects. The findings also suggest interesting interactions between top down (organizer comments and post prompts) and bottom up (new joiners and returning participants) factors. For example, weekly post prompts had different influences on returning vs. new participants. Courses that had more weekly post prompts and more returning participants had lower numbers of active commenters and comments contributed per commenter (Table 5). However, courses with more post prompts and new joiners saw slightly more active commenters. Perhaps new joiners need pages with explicit instructions and invitations to participate, as they are new and have not yet gotten involved in ongoing discussions or developed relationships with others in the course.

Organizer comments had different influences on returning vs. new participants. Courses with more organizer comments and returning participants were associated with more active commenters. However, organizer comments and new joiners did not significantly influence more course activity. Thus, with returning members, interacting with course organizers (rather than broad course prompts) might be the best strategy to motivate them to be active contributors.

\section{Discussion}

Using log data from one of the foremost open, peer-to-peer learning platforms (P2PU), this study examined some factors that affect learner participation. Our findings show that rather than focusing on the number of comments contributed to a course, it is more effective to identify ways to increase the number of active members and to encourage these active members to contribute more to the learning group.

The study suggests several design strategies for P2PU to better develop active participants and encourage more contribution. In spite of P2PU's open, bottom-up approach, top-down organizer driven approaches, such as organizer comments and pages containing post prompts have potential as strategies for promoting participation. Course organizers who contribute to a course have a significant, positive 
influence on others' course activity. Similarly, designing course pages that explicitly prompt participants to actively participate also increases the number and extent of contribution. These findings coalesce with prior e-learning research in formal university settings [10] and suggest that even in open learning platforms, leaders must emerge that help to design, guide, and facilitate the learning process. Formal e-learning settings often have already assigned instructors. One challenge then for open, peer-to-peer environments is the cultivation of individuals who are skilled in leading educational endeavors.

Bottom up mechanisms arising from the choices of individual members were also positively related to more active courses. Having participants who choose to return and visit the course was highly related to the level of course activity. This finding makes sense because having a larger population of return visitors means more individuals could decide to be active.

Moreover, while the findings suggest that participant choice and behaviors are primary factors in participation, they also imply that different participants are affected in different ways by top down actions. Conversion of lurkers to active contributors appears to be different for new joiners vs. returning participants. For new joiners, having clear prompts in course pages is related to more active participation. For returning participants, more organizer activity promotes greater participant activity. This suggests that, at least in these courses, use of explicit discussion prompts and organizer comments are complementary strategies.

Limitations and Future Opportunities. The limitations of this particular P2PU dataset illustrate how the structure of data culled from online platforms can profoundly shape what types of analytics can be performed. For example, members were not given unique usernames across all courses (i.e. username 3 in course 1 was not the same person as username 3 in course 7). This feature of the dataset made it impossible to test hypotheses about members' participation in multiple courses. In addition, the data did not distinguish page-specific comment data or indicate which pages users posted comments to. As a result, analysis of individual participation activity was limited to group level aggregate measures.

Such data features have methodological and conceptual implications for future work. For example, while we often talk about a single course, individuals are rarely involved in only one. Even if members only actively participate in one, the presence of and activity in other courses may affect their behavior [5]. Methodologically, theoretically, and practically it is important for data to be collected in such a way that cross group effects within collective learning platforms can be taken into account in future work. For example, what are the effects of participating in multiple courses on participation levels? Perhaps joining multiple courses impedes an individual's ability to participate deeply in any one course. Partnering with P2PU and other open education platforms will allow for future studies that analyze finer-grain user data to explore richer models of learner participation.

In this study we consider two course features: posting prompts and organizer comments. These affordances are also present in existing, formal elearning environments and our finding that leadership and course design in P2PU positively influences participation coalesces with prior research [10]. However, as a rapidly evolving platform, P2PU is constantly incorporating new features and structures. It is now possible to create ongoing "challenges" that are not time-bound courses but are persistent on the site. Members can also earn badges by completing certain challenges. Future work should examine how these new features influence learner participation.

As noted earlier, participation comes in many forms. We were limited to consider counts of comment contribution. Future work could also consider richer measures of participation and examine how different forms of participation relate to learning outcomes. Prior work in formal e-learning initiatives has considered outcomes such as course grades [8]. We are also interested in thinking about literacy as an outcome of participating in peer-to-peer learning platforms. For example, how do learner experiences in P2PU relate to individuals developing into skilled peer facilitators, course creators, or mentors in the community? Do learners in P2PU pursue future challenges, badges, and courses as a product of their past experiences? These participatory literacies become important to sustain user-generated, peer-to-peer environments and become vital outcomes for this informal learning setting.

Finally, this study is an analysis of P2PU's School of Education. The 7 courses were part of a cluster, with a specific implementation and participant group. While the results are intriguing, cautions should be used when generalizing these results for other platforms or learning environments. For example, it may be the case that teacher presence in a formal online course, which is analogous to organizer comments in the P2PU context, might be more influential than seen here [10]. Future study of learning and participation dynamics across different platforms is needed to better understand how technology, design, and contextual factors affect learner participation.

\section{Conclusion}

Online education is evolving and access to online learning opportunities is becoming more widespread. 
Universities and K-12 schools are no longer the only institutions that provide structured learning opportunities. Peer-to-peer platforms such as P2PU allow collectives of individuals to learn from one another. Large-scale data culled from such platforms provide researchers an opportunity to ask new questions about how participation, collaboration, and ultimately learning develop in these open platforms. This study is an initial step in the exploration of the potential of the combination of networked education, "big data", and learning analytics.

\section{References}

[1] J. Arguello, B. S. Butler, E. Joyce, R. Kraut, K. S. Ling, C. Rosé, and X. Wang, "Talk to me: foundations for successful individual-group interactions in online communities", Proceedings of CHI 2006, New York, NY, USA, pp. 959-968, 2006.

[2] R. M. Bernard, P. C. Abrami, E. Borokhovski, C. A. Wade, R. M. Tamim, M. A. Surkes, and E. C. Bethel, "A meta-analysis of three types of interaction treatments in distance education", Review of Educational Research, vol. 79, no. 3, pp. 1243-1289, 2009.

[3] J. S. Brown and R. P. Adler, "Minds on Fire: Open Education, the Long Tail, and Learning 2.0", Educause, Washington, DC, pp. 17-32, 2008.

[4] B. S. Butler, L. Sproull, S. Kiesler, and R. E. Kraut, "Community Effort in Online Groups: Who Does the Work and Why?", In S. Weisband \& L. Atwater (Eds.), Leadership at a Distance, Lawrence Erlbuam Associates, Mahwah, NJ, 2007.

[5] B. S. Butler and X. Wang, "The Cross-Purposes of Crossposting: Boundary Reshaping Behavior in Online Discussion Communities", Information Systems Research, 2011, doi:10.1287/isre.1110.0378

[6] C. Christensen, C. W. Johnson, and M. B. Horn, Disrupting Class: How Disruptive Innovation will Change the Way the World Learns. McGraw-Hill, New York, NY, 2008.

[7] J. Cummings, B. S. Butler, and R. E. Kraut, "The Quality of Social Ties Online", Communications of the ACM, vol. 45, no. 7, pp. 103-109, 2002.

[8] J. Davies and M. Graff, "Performance in e-learning: Online participation and student grades", British Journal of Educational Technology, vol. 36, no. 4, pp. 657-663, 2005.

[9] S. Dawson, "A study of the relationship between student communication interaction and sense of community", Internet and Higher Education, vol. 9, pp. 153-162, 2006.

[10] D. R. Garrison and J. B. Arbaugh, "Researching the community of inquiry framework: Review, issues, and future directions", The Internet and Higher Education, vol. 10, pp. 157-172, 2007.
[11] C. Haythornthwaite, "Facilitating collaboration in online learning", Journal of Asynchronous Learning, vol. 10, no. 1, http://sloanconsortium.org/jaln/v10n1/facilitatingcollaboration-online-learning, 2006.

[12] C. Haythornthwaite, M. M. Kazmer, J. Robins, and S. Shoemaker, "Community development among distance learners: Temporal and technological dimensions", Journal of Computer-Mediated Communication, vol 6, no. 1, http://onlinelibrary.wiley.com/doi/10.1111/j.10836101.2000.tb00114.x/full.

[13] S. Hrastinski, "What is online learner participation? A literature review", Computers \& Education, vol. 51, pp. 1755-1765, 2008.

[14] S. Hrastinski, "The theory of online learning as online participation", Computers \& Education, vol. 52, pp. 7882, 2009.

[15] Y. B. Kafai and K. A. Peppler, "Beyond Small Groups: New Opportunities for Research in Computer-Supported Collective Learning", Proceedings of the $9^{\text {th }}$ International CSCL Conference, Hong Kong, China, pp. 17-24, 2011.

[16] A. J. Kim, Community Building on the Web: Secret Strategies for Successful Online Communities ( $1^{\text {st }} \mathrm{ed}$.), Addison-Wesley Longman Publishing Co., Inc., Boston, MA, 2000.

[17] R. Kling and C. Courtright, "Group behavior and learning in electronic forums: A sociotechnical approach", The Information Society, vol. 19, pp. 221235, 2003.

[18] R. E. Kraut and P. Resnick, Building successful online communities: Evidence-based social design. The MIT Press, Cambridge, MA, 2012.

[19] S. Krishnamurthy, "Cave or community?: An empirical examination of 100 mature open source projects", First Monday, vol. 7, no. 6, 2002.

[20] A. McAuley, C. Stewart, G. Siemens, and D. Cormier. "The mooc model for digital practice", SSHRC Knowledge Synthesis Grant on the Digital Economy, 2010.

[21] B. Nonnecke, and J. Preece, "Lurker demographics: Counting the silent", Proceedings of CHI 2000, The Hague: ACM, 2000.

[22] K. J. Preacher, and A. F. Hayes, "Asymptotic and resampling strategies for assessing and comparing indirect effects in multiple mediator models", Behavioral Research Methods, vol. 40, pp. 879-891, 2008.

[23] J. Preece, Online Communities: Designing Usability and Supporting Socialbility ( $1^{\text {st }}$ ed.), John Wiley \& Sons, Inc., New York, NY, 2000.

[24] J. Preece, and B. Shneiderman, "The Reader-to-Leader Framework: Motivating Technology-Mediated Social Participation," AIS Transactions on Human-Computer Interaction, vol. 1, no. 1, pp. 13-32, 2009.

[25] S. Rafaeli and F. Sudweeks, "Networked Interactivity", Journal of Computer-Mediated Communication, vol. 2, no. 4 ,

http://jcmc.indiana.edu/vol2/issue4/rafaeli.sudweeks.ht 